syndromes. In: J. B. Stanbury, J. B. Wyngaarden, D. S. Fredrickson, J. L. Goldstein, and M. S. Brown (Eds.): The Metabolic Basis of Inherited Disease. p. 402 (McGraw-Hill Book Company, New York, 1983).

24. The authors express their gratitude to L. B. Russel at the Oak Ridge National

Laboratory, Oak Ridge, USA, for sending us the spf-mice and thank Miss K.

Pallmert, Mrs. E. Schneider, Miss U. Pfister and Miss M. Gradwohl for their skillful technical assistance. The work was supported by grant 3.551-0.79 of the Swiss National Science Foundation.

25. Requests for reprints should be addressed to: Dr. C. Bachmann, CZL, Inselspital, CH-3010 Bern, Switzerland.

26. Received for publication January 11,1983

27. Accepted for publication July 13,1983 .

\title{
Mathematical Function for Maternal Age in Down's Syndrome
}

\author{
JOHN S. H. TAY ${ }^{(8)}$ AND WILLIAM C. L. YIP \\ Department of Paediatrics, National University of Singapore, Singapore, Republic of Singapore
}

\section{Summary}

The purpose of this study is to fit a mathematic function to the observed risk figures for Down's syndrome at various maternal ages. Data from the New York State and Swedish studies were used. It was found that the estimated risks fitted the exponential relationship very well, with a correlation coefficient of over 0.94 . An even better correlation was found (over 0.97 ) for each 5-yr period in the New York State study. The exponential relationship was given by: $I=a e^{b x}$, where $1 / I$ is the estimated risk; $x$, the maternal age in years; and $a$ and $b$, the constants. In both studies there was considerable variation in the values of $a$ and $b$ with maternal age as well as an excellent correlation between $\ln a$ and b for the 5-yr periods. This function may be used to test various hypotheses for the effect of maternal age in Down's syndrome.

An increased incidence of Down's syndrome among the children of older mothers has been well documented. The relationship between the incidence and maternal age is far from linear. A gradual increase in rates of Down's syndrome with maternal age is observed up to about age 30 or 31 yr (3) and a steeper increase is seen thereafter, reaching a figure of 1 in 12 at $49 \mathrm{yr}$ (2). Various hypotheses have been proposed to explain this maternal age effect: maternal exposure to diagnostic radiographs of the abdomen, virus-induced disturbance of chromosomal segregation, "over-ripeness" of the ovum due to delayed fertilization, increase in the frequency of thyroid autoantibodies, and genetic predisposition to non-disjunction (7). The exact mechanism is unclear.

The purpose of this paper is to present a mathematic function to fit the observed risks of Down's syndrome at various maternal ages. This function could then be used to test the likelihood of the various hypotheses.

\section{CONSTRUCTION OF THE MATHEMATIC FUNCTION}

The results of the New York State study (2) and the Swedish study (3) are used (Table 1). Inspection of the risk figures suggests an exponential relationship:

$$
\mathrm{I}=\mathrm{ae}^{\mathrm{bx}}
$$

where $1 / \mathrm{I}$ is the estimated rate and $\mathrm{x}$ the maternal age (yr), and $a$ and $b$ are constants.
The computer program EXPONENTIAL REGRESSION (1) (4) was used on an Apple II microcomputer. This program finds the coefficients of an equation for an exponential curve. The equation is in the following form: $f(x)=a^{*} e^{b x}$, where $a$ and $b$ are the calculated coefficients. The equation coefficients, coefficient of correlation and standard error of $b$ are calculated. The program also allows for the prediction of values of $y$ for given values of $x$, using the calculated equation coefficients.

The standard error of $b$ is calculated according to Armitage (1): the variance of $b$ is given by

$$
\operatorname{var}(b)=s_{o}^{2} / \Sigma(x-\bar{x})^{2}
$$

where $\mathrm{s}_{\mathrm{o}}{ }^{2}$, the residual mean square $=\frac{\Sigma(\mathrm{y}-\mathrm{Y})^{2}}{\mathrm{~N}-2}$.

The expression $\Sigma(y-Y)^{2}$, the residual sum of squares, is obtained as follows:

$$
\Sigma(\mathrm{y}-\mathrm{Y})^{2}=\Sigma(\mathrm{y}-\overline{\mathrm{y}})^{2}-\frac{\{\Sigma(\mathrm{x}-\overline{\mathrm{x}})(\mathrm{y}-\overline{\mathrm{y}})\}^{2}}{\Sigma(\mathrm{x}-\overline{\mathrm{x}})^{2}}
$$

The $95 \%$ confidence limits for the predicted values $(Y)$ are given by:

$$
Y \pm t_{N-2.0 .05} s_{o} \sqrt{\frac{1}{N}+\frac{\left(x_{o}-\bar{x}\right)^{2}}{\Sigma(x-\bar{x})^{2}}}
$$

for $\mathrm{N}-2$ degrees of freedom on the $t$ distribution. The variable $x_{o}$ is the value of $x$ (maternal age) at which the predicted risk is to be determined. The width of the confidence interval increases with $\left(\mathrm{x}_{\mathrm{o}}-\overline{\mathrm{x}}\right)$, and is a minimum when $\mathrm{x}_{\mathrm{o}}=\overline{\mathrm{x}}$.

The results of the New York State study fitted the exponential model very well, with a correlation coefficient of 0.9752 over the whole age range (20-49 yr) (Table 2). The standard error of $b$, however, was relatively large $(0.3627)$. When the exponential model was applied to the data in segments of 5-yr periods, it was found that the correlation was even better. More significantly, the standard error of $b$ was much lower (Table 2). The equation coefficients $a$ and $b$ generated in this way were used to predict the risk figures (Table 1). It was found that the predicted values were much closer to the observed values when the equation coefficients ( $a$ and $b$ ) calculated for 5 -yr periods were used (as would be expected from the smaller standard errors of $b$ ).

Large fluctuations were found in the values of $a$ and $b$ calcu- 
Table 1. Estimated rates of Down syndrome (results of New York State and Swedish studies)

\begin{tabular}{|c|c|c|c|c|}
\hline \multirow{2}{*}{$\begin{array}{c}\text { Maternal } \\
\text { age }(\mathrm{yr})\end{array}$} & \multicolumn{2}{|c|}{ Estimated risk } & \multicolumn{2}{|c|}{ Interpolation for $(\mathrm{N})$} \\
\hline & $(\mathrm{S})^{*}$ & $(\mathrm{~N}) \dagger$ & (i) $\ddagger$ & (ii)§ \\
\hline 20 & $1 / 1727$ & $1 / 1925$ & $1 / 3491$ & $1 / 1893$ \\
\hline 21 & $1 / 1321$ & $1 / 1695$ & $1 / 2921$ & $1 / 1718$ \\
\hline 22 & $1 / 1294$ & $1 / 1540$ & $1 / 2444$ & $1 / 1559$ \\
\hline 23 & $1 / 1168$ & $1 / 1410$ & $1 / 2045$ & $1 / 1415$ \\
\hline 24 & $1 / 1460$ & $1 / 1300$ & $1 / 1711$ & $1 / 1284$ \\
\hline 25 & $1 / 1252$ & $1 / 1205$ & $1 / 1432$ & $1 / 1200$ \\
\hline 26 & $1 / 1088$ & $1 / 1125$ & $1 / 1198$ & $1 / 1126$ \\
\hline 27 & $1 / 1355$ & $1 / 1050$ & $1 / 1003$ & $1 / 1057$ \\
\hline 28 & $1 / 1034$ & $1 / 990$ & $1 / 839$ & $1 / 992$ \\
\hline 29 & $1 / 936$ & $1 / 935$ & $1 / 702$ & $1 / 931$ \\
\hline 30 & $1 / 1258$ & $1 / 885$ & $1 / 588$ & $1 / 940$ \\
\hline 31 & $1 / 549$ & $1 / 825$ & $1 / 491$ & $1 / 800$ \\
\hline 32 & $1 / 958$ & $1 / 725$ & $1 / 411$ & $1 / 680$ \\
\hline 33 & $1 / 491$ & $1 / 590$ & $1 / 344$ & $1 / 578$ \\
\hline 34 & $1 / 477$ & $1 / 465$ & $1 / 288$ & $1 / 491$ \\
\hline 35 & $1 / 492$ & $1 / 365$ & $1 / 241$ & $1 / 364$ \\
\hline 36 & $1 / 387$ & $1 / 285$ & $1 / 202$ & $1 / 286$ \\
\hline 37 & $1 / 218$ & $1 / 225$ & $1 / 169$ & $1 / 225$ \\
\hline 38 & $1 / 196$ & $1 / 175$ & $1 / 141$ & $1 / 177$ \\
\hline 39 & $1 / 151$ & $1 / 140$ & $1 / 118$ & $1 / 139$ \\
\hline 40 & $1 / 82$ & $1 / 110$ & $1 / 99$ & $1 / 109$ \\
\hline 41 & $1 / 79$ & $1 / 85$ & $1 / 83$ & $1 / 86$ \\
\hline 42 & $1 / 56$ & $1 / 67$ & $1 / 69$ & $1 / 67$ \\
\hline 43 & $1 / 88$ & $1 / 53$ & $1 / 58$ & $1 / 53$ \\
\hline 44 & $1 / 28$ & $1 / 41$ & $1 / 48$ & $1 / 41$ \\
\hline 45 & $1 / 18$ & $1 / 32$ & $1 / 41$ & $1 / 32$ \\
\hline 46 & $1 / 12$ & $1 / 25$ & $1 / 34$ & $1 / 25$ \\
\hline 47 & $1 / 35$ & $1 / 20$ & $1 / 28$ & $1 / 20$ \\
\hline 48 & $1 / 10$ & $1 / 16$ & $1 / 24$ & $1 / 16$ \\
\hline 49 & $\ldots$ & $1 / 12$ & $1 / 20$ & $1 / 12$ \\
\hline
\end{tabular}

*(S), Swedish study.

$\dagger(\mathrm{N})$, New York State study.

$\ddagger($ i), Predicted values using the values of a and b calculated over the whole age range (20-49 yr), see Table 2.

$\S$ (ii), Predicted values using the values of $a$ and $b$ calculated from 5yr periods (Table 2).

Table 2. Exponential relationship applied to the New York State study*

\begin{tabular}{crccc}
\hline $\begin{array}{c}\text { Age range } \\
\text { (yr) } \dagger\end{array}$ & Value of a & Value of $\mathrm{b}$ & $\begin{array}{c}\text { Correlation } \\
\text { coefficient } \ddagger\end{array}$ & $\begin{array}{c}\text { Standard } \\
\text { error of } \\
\mathrm{b}\end{array}$ \\
\hline $20-24$ & 13,149 & -0.0969 & 0.9959 & 0.0161 \\
$25-29$ & 5,872 & -0.0635 & 0.9990 & 0.0053 \\
$30-34$ & 122,200 & -0.1622 & 0.9774 & 0.0640 \\
$35-39$ & $1,640,600$ & -0.2404 & 0.9998 & 0.0077 \\
$40-44$ & $1,944,031$ & -0.2446 & 0.9998 & 0.0078 \\
$45-49$ & $1,631,343$ & -0.2408 & 0.9989 & 0.0206 \\
$20-49$ & 123,185 & -0.1782 & 0.9752 & 0.3627 \\
\hline
\end{tabular}

$* \mathrm{I}=\mathrm{ae}^{\mathrm{bx}}$, where $1 / \mathrm{I}$ is the estimated rate and $\mathrm{x}$ is the maternal age (yr). $a$ and $b$ are constants.

$\dagger$ Regression equation for $\ln a$ and $b$ over the whole age range (20-49 yr): In $\mathrm{a}=6.48-32.55 \mathrm{~b}$.

$\ddagger$ Correlation coefficient between $\ln \mathrm{a}$ and $\mathrm{b}=0.9994$ (Student's $t=$ 56.06 and $P=0.0002$ ). lated over the various 5-yr intervals (Table 2). Close correlation, however, was found between In a and $b$ (correlation coefficient of -0.9994 , Student's $t=56.06$ and $P=0.0002$ ). The regression equation for In a and b over the age range 20-49 yr:

$$
\text { In } \mathrm{a}=6.48-32.55 \mathrm{~b}
$$

The results of the Swedish study also fit the exponential model very well (over the entire age range), with a correlation coefficient of 0.9432 (Table 3 ). The standard error of $b(0.5508)$ was larger than that for the New York State study. The results of 5-yr periods, however, did not fit the exponential model as well (correlation coefficients varying from 0.1804 to 0.9762 ), and the standard errors of $b$ were also very large. This is probably the result of larger sampling erors in the study. The $95 \%$ confidence limits for the New York State and the Swedish studies are shown in Figures 1 and 2, respectively.

Despite the poorer correlation within the 5-yr periods, the values of the equation coefficients $a$ and $b$ for the whole age range $(a=129,127$ and $b=-0.1803)$ were remarkably close to those found in the New York State study $(a=123,185$ and $b=$ -0.1782 ). The regression equation for $\ln a$ and $b$ in the Swedish study (ln $\mathrm{a}=5.62-35.91 \mathrm{~b})$ was also very similar to that in the New York State study. The correlation coefficient for $\ln \mathrm{a}$ and $\mathrm{b}$ was -0.9608 (Student's $t=6.94$ and $P=0.0036$ ).

\section{SIGNIFICANCE OF THE EXPONENTIAL RELATIONSHIP}

The results of the New York State and Swedish studies (studies which were independent of each other) fit the exponential model very well. Despite the large standard errors of estimate for the 5yr periods in the Swedish study, it is significant that there is close correlation between $\ln \mathrm{a}$ and $\mathrm{b}$ in both studies. From the formula:

$$
I=\mathrm{ae}^{\mathrm{bx}}
$$

we have $\ln \mathrm{a}=\ln \mathrm{I}-\mathrm{bx}$. From basic principles we can expect a close correlation between $\ln a$ and $b$ if the exponential relationship holds true.

The exponential relationship may be used to test the various hypotheses for the maternal age effect in Down's syndrome. The mechanism for the maternal age effect must be consistent with the following three features. 1) the observed risk figures fit the exponential model $I=a^{*} \exp (b x)$ very well. 2 ) There is considerable variation in the values of $a$ and $b$ with maternal age, calculated for 5-yr periods. 3) There is close correlation between In $a$ and $b$.

It is apparent from the exponential relationship above that any hypothesis that advocates a mechanism of action in an "additive" manner will probably be incorrect. For example, in an "additive" model, if the effect of the causative agent in the

Table 3. Exponential relationship applied to the Swedish study*

\begin{tabular}{crccc}
\hline $\begin{array}{c}\text { Age range } \\
(\mathrm{yr}) \dagger\end{array}$ & Value of a & Value of $\mathrm{b}$ & $\begin{array}{c}\text { Correlation } \\
\text { coefficient } \ddagger\end{array}$ & $\begin{array}{c}\text { Standard } \\
\text { error of } \\
\mathrm{b}\end{array}$ \\
\hline $20-24$ & 3,794 & -0.0459 & 0.4913 & 0.1486 \\
$25-29$ & 6,236 & -0.0635 & 0.6749 & 0.1268 \\
$30-34$ & 490,321 & -0.2052 & 0.7387 & 0.3420 \\
$35-39$ & $20,587,197$ & -0.3047 & 0.9762 & 0.1235 \\
$40-44$ & 361,998 & -0.2066 & 0.6823 & 0.4042 \\
$45-49$ & 683 & -0.0804 & 0.1804 & 0.6931 \\
$20-49$ & 129,127 & -0.1803 & 0.9432 & 0.5508 \\
\hline
\end{tabular}

${ }^{*} \mathrm{I}=\mathrm{ae}{ }^{\mathrm{bx}}$, where $1 / \mathrm{I}$ is the estimated rate and $\mathrm{x}$ is the maternal age (yr). $a$ and $b$ are constants.

$\dagger$ Regression equation for $\ln \mathrm{a}$ and $\mathrm{b}$ over the whole age range (20-49 yr) $\ln \mathrm{a}=5.62-35.91 \mathrm{~b}$.

$\ddagger$ Correlation coefficient between $\ln$ a and $\mathrm{b}=-0.9608$ (Student's $t=$ 6.94 and $P=0.0036$ ). 


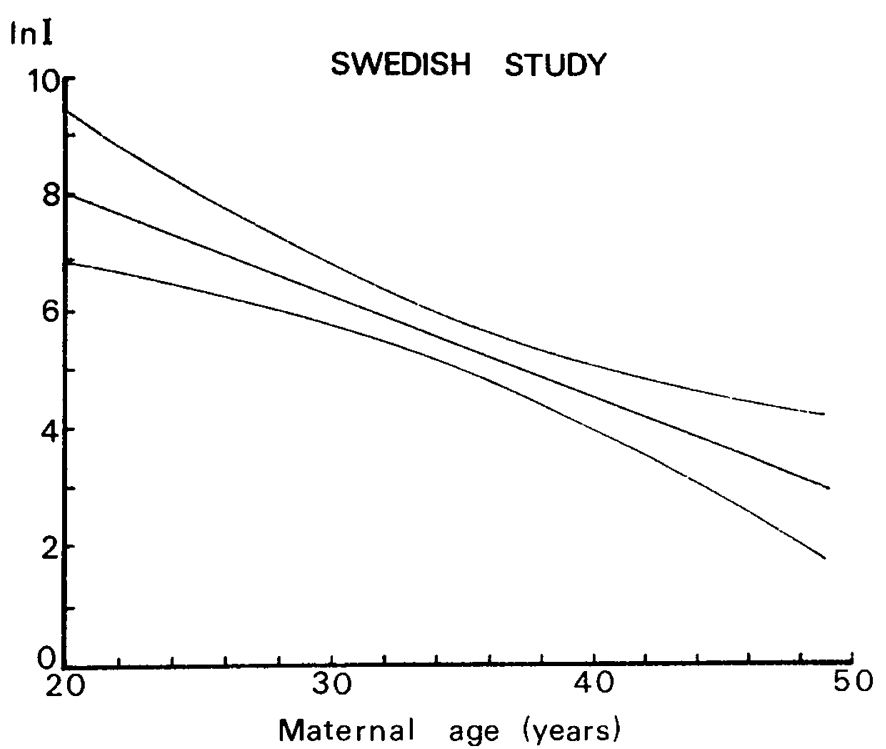

Fig. 1. Swedish study. Predicted values for $\ln I$ (where $1 / I$ is the estimated risk) and $95 \%$ confidence limit

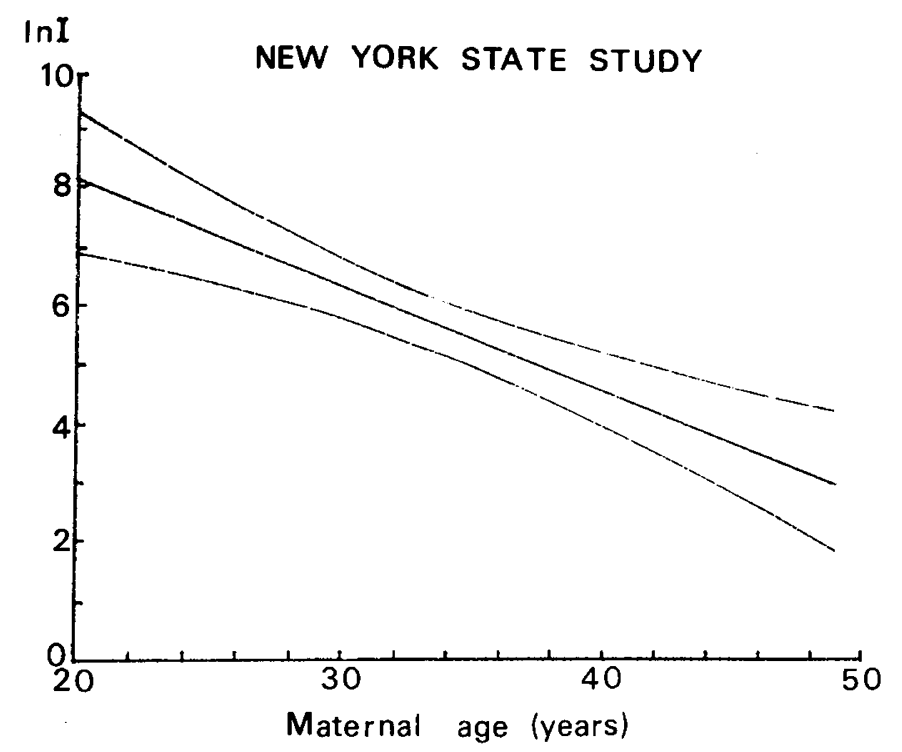

Fig. 2. New York State study. Predicted values for $\ln I$ (where $1 / 1$ is - the estimated risk) and $95 \%$ confidence limit.

ith year on the mother is $r_{i}$, the total effect $(T)$ will be given by a summation over all the years $(k)$ :

$$
T=\sum_{i=1}^{k} r_{i}
$$

Such a model will not generate data to fit an exponential relationship.

A "multiplicative" model for the mode of action is more likely to be correct, for example (using the same symbols as above):

$$
\mathrm{T}=\prod_{\mathrm{i}=1}^{\mathrm{k}} \mathrm{r}_{\mathrm{i}}
$$

It can be shown that a model like this can generate data that will fit the exponential relationship very well, and possibly allow for a considerable variation in the values of $a$ and $b$ as well as close correlation between $\ln a$ and $b$.

Although a good fit of data has been demonstrated, the basic character of the underlying phenomena may not necessarily be "exponential" unless supportive biologic evidence is available. It is our hope that more research on the basic mechanisms of the maternal age effect will be forthcoming.

There is some evidence that there is also a paternal age effect on the risk of Down's syndrome $(5,6)$. This appears to be independent of the maternal age effect. Unfortunately, data on the paternal age effect is not as extensive as that on the maternal age effect, and it is not easy at present to construct a mathematic function based on the data available. If the paternal age has a similar effect as maternal age on the risk of Down's syndrome, then the above "multiplicative" model could be extended as follows (assuming that the paternal age effect is independent of the maternal age effect):

$$
\mathrm{T}=\prod_{\mathrm{i}=1}^{\mathrm{k}} \mathrm{r}_{\mathrm{i}}+\prod_{\mathrm{i}=1}^{\mathrm{k}} \mathrm{s}_{\mathrm{i}}
$$

where the effect of the causative agent in the ith year on the father is $s_{i}(5)$.

\section{REFERENCES AND NOTES}

1. Armitage, P.: Statistical Methods in Medical Research. pp. 150-165. (Blackwell Scientific Publications, Oxford, London, Edinburgh, and Melbourne 1971).

2. Hook, E. B. and Chambers, G. M.: Estimated rates of Down's syndrome in live births by one year maternal age intervals for mothers aged 20-29. Birth defects, 13(3A): 123-141 (1977).

3. Hook, E. B and Lindsjo, A.: Down's syndrome in Live Births by Single Year Maternal Age Interval in a Swedish Study: comparison with results from a New York State Study. Am. J. Hum. Genet., 30: 19 (1978).

4. Poole, L. and Borchers, M.: Some common basic programs. 3rd ed., pp. 156157 (Osborne/McGraw-Hill, Berkeley, California, 1979).

5. Stene, J., Fisher, G., Stene, E., Mikkelsen, M., and Petersen, E.: Paternal age effect in Down's syndrome. Ann. Human Genet. 40: 299 (1977).

6. Tay, J. S. H., Yip, W. C. L., Quak, S. H., and Joseph, R.: Paternal age and Down's syndrome. Proceedings of the 4th Asian Congress of Padiatrics, Seoul, Korea, 1982, p. 209.

7. Uchida, I. A. and Summitt, R. L.: Chromosomes and their abnormalities. In: Nelson, W. E., Vaughan, V. C., McKay, R. J., and Behrman, R. E. Ed.: Nelson Textbook of Padiatrics. pp. 352-355 (W. B. Saunders Company, Philadelphia, London, and Toronto 1979).

8. Requests for reprints should be addressed to: Prof. John Tay, University Dept. of Paediatrics, Singapore General Hospital, Outram Road, Singapore, Republic of Singapore.

9. Received for publication January 6, 1983.

10. Accepted for publication June 27, 1983. 